\title{
Occupational injuries in Canadian youth: an analysis of 22 years of surveillance data collected from the Canadian Hospitals Injury Reporting and Prevention Program
}

\author{
B. Pratt, MPH (1, 2); J. Cheesman (1); C. Breslin, PhD (3); M. T. Do, PhD (1, 2)
}

This article has been peer reviewed.

Tweet this article

\section{Abstract}

Introduction: Inexperience, inadequate training and differential hazard exposure may contribute to a higher risk of injury in young workers. This study describes features of work-related injuries in young Canadians to identify areas for potential occupational injury prevention strategies.

Methods: We analyzed records for youth aged 10-17 presenting to Canadian Hospitals Injury Reporting and Prevention Program (CHIRPP) emergency departments (EDs) from 1991-2012. We classified work-related injuries into job groups corresponding to National Occupational Classification for Statistics 2006 codes and conducted descriptive analyses to assess injury profiles by job group. Age- and sex-adjusted proportionate injury ratios (PIRs) and 95\% confidence intervals (CIs) were calculated to compare the nature of injuries between occupational and non-occupational events overall and by job group.

Results: Of the 6046 injuries $(0.72 \%$ of events in this age group) that occurred during work, $63.9 \%$ were among males. Youth in food and beverage occupations ( $54.6 \%$ males) made up $35.4 \%$ of work-related ED visits and $10.2 \%$ of work-related hospital admissions, while primary industry workers (76.4\% males) made up $4.8 \%$ of workrelated ED visits and $24.6 \%$ of work-related hospital admissions. PIRs were significantly elevated for burns (9.77, 95\% CI: 8.94-10.67), crushing/amputations (6.72, $95 \%$ CI: 5.79-7.80), electrical injuries $(6.04,95 \%$ CI: 3.64-10.00), bites $(5.09$, $95 \%$ CI: $4.47-$ $5.79)$, open wounds $(2.68,95 \%$ CI: $2.59-2.78)$ and eye injuries (2.50, $95 \%$ CI: $2.20-2.83)$ in occupational versus non-occupational events. These were largely driven by high proportional incidence of injury types unique to job groups.

Conclusion: Our findings provide occupation group-specific information on common injury types that can be used to support targeted approaches to reduce incidence of youth injury in the workplace.

Keywords: adolescent, injury surveillance, occupational injuries, young workers, youth injuries

\section{Introduction}

Many youth get jobs for the intrinsic and material benefits-to acquire skills and earn money. ${ }^{1}$ In 2014 , nearly half of 15 to 19 year olds, or about 840000 Canadians, were in the workforce. ${ }^{2}$ However, the risk of injury among people in this age group often counters the benefits of working. Between 2011 and 2013, Canadian workers' compensation (WC) boards recorded 20 fatalities among 15- to 19-year-old workers; ${ }^{3} 23996$ time-loss injury claims were accepted in this age group alone. ${ }^{4}$
Highlights

- Information about injuries of children who come to the emergency departments of 11 pediatric hospitals and of 6 general hospitals across the country is recorded in the Canadian Hospitals Injury Reporting and Prevention Program (CHIRPP).

- We used CHIRPP data from 1991-2012 to find out how 10- to 17-year-old working youth were injured on the job.

- Youth who work in the food/beverage industry make up the majority of those with work injuries who come to hospital emergency departments.

- Hospital admissions due to work injuries are mainly among youth who work in trades (construction/ repair, machinist/metal working/electrical and general labourers), manufacturing and primary industry.

- Young food/beverage and construction workers experienced a significantly greater proportional incidence of burns; delivery and childcare workers present more often for bites; and eye and crushing/amputation injuries were most common in young trades workers, material handlers/ vehicle operators and primary industry workers.

- Compared to non-work injuries, incidence of several injury types, notably bites and burns, varied by age within young workers.

Although occupational injury data for workers younger than 15 are sparse, surveys of American and Canadian middle-schoolers

Author references:

1. Surveillance and Epidemiology Division, Public Health Agency of Canada, Ottawa, Ontario, Canada.

2. Dalla Lana School of Public Health, University of Toronto, Toronto, Ontario, Canada.

3. Institute of Work and Health, Toronto, Ontario, Canada.

Correspondence: Minh T. Do, Surveillance and Epidemiology Division, Public Health Agency of Canada, 785 Carling Ave, Ottawa, ON K1A 0K9; Email: Minh.T.Do@phac-aspc.gc.ca 
found that $18 \%$ of working 10 - to 14 year olds reported work injuries from summer jobs ${ }^{5}$ and $49.7 \%$ of wage-earning 12 - to 14 year olds reported work injuries in the past year. ${ }^{6}$

Impairments resulting from injuries that occur early in the work life can impact future work abilities and have long-term health effects. ${ }^{7}$ Young people with work injuries have more annual general practitioner visits compared to those without work injuries. ${ }^{8}$ Across occupational categories, youth employed in the manual and goods-producing sector have a greater risk of sustaining injuries that result in work disability absence or increased lost-time WC claims compared to those in the service sector. ${ }^{7,9}$

Although claims data are informative, they do not include the injuries of young workers who are not covered by or are ineligible for WC. Since youth are more likely to engage in temporary, casual, contract or seasonal work than adults $^{10}$ and the youngest workers frequently work in informal or self-employment arrangements such as farm work, babysitting or with family businesses ${ }^{5}$ that are not compulsorily or reliably covered in all provinces, ${ }^{11}$ claims data may underestimate youth injuries. This is compounded by general underreporting of work-related injuries by young employees because they fear reprisals, feel powerless or think their employer disregards concerns or because they are not aware of the reporting channels. ${ }^{12-14}$

A 2005 paper described the frequency and distribution of occupational injuries among youth using data collected from the Canadian Hospitals Injury Reporting and Prevention Program (CHIRPP). ${ }^{15}$ The emergency department (ED) surveillance sites engaged in this system capture a larger portion of the "base" of the injury pyramid by including events not severe enough to result in hospitalization, irrespective of WC coverage or claim submission status. Moreover, data from CHIRPP provide a rich source of information on clinical characteristics and a detailed narrative describing the circumstances surrounding the injury event.

In the 10 years since the original paper's publication, this updated analysis benefits from an increase in statistical power from the greater number of cases captured over time, and includes comparative analyses of injury characteristics between occupational and non-occupational injuries.

Given the substantial burden posed by occupational injuries in this population, identifying injury characteristics and risk factors unique to youth has implications for improving the health of the current and future workforce, as well as preventing prolonged health care use relating to work injuries. Using 22 years of data from CHIRPP, we describe demographic and job-related features of youth occupational injuries, including comparisons to non-occupational injuries and between occupational groups.

\section{Methods}

\section{Data source}

CHIRPP, an ED-based injury surveillance system under the custodianship of the Public Health Agency of Canada, was initiated in 1990. Participating sites across Canada collect details on injuries and poisonings from the EDs of 11 pediatric and 6 general hospitals. This information is recorded on a CHIRPP reporting form that consists of one page completed by the patient (or on behalf of the patient) describing the circumstances of the injury and a second page completed by the physician noting clinical features of the injury. Forms are centrally coded by trained personnel within the Public Health Agency of Canada. Since 2010, report form entry transitioned to electronic CHIRPP (eCHIRPP) record capture; forms are entered directly by site coordinators to a central webbased application.

Data collected by CHIRPP have been previously described and evaluated as being of good quality when used carefully for public health research purposes. ${ }^{16}$

\section{Study population}

Youth aged 10 to 17 years, inclusive, who had completed a CHIRPP form between January 1, 1991, and December 31, 2012, were eligible for inclusion in our analysis. Age was restricted to less than 18 years as this is the typical age below which statutory restrictions on employment in Canada apply. ${ }^{6}$ The lower boundary of 10 years was set to capture youth reporting more informal work arrangements. ${ }^{5}$ Records with missing date of birth ( $n=14$ ) were ineligible for the initial data extraction.

\section{Occupational injury classification}

Occupational injuries were identified based on self-report, through a yes/no question in the paper and eCHIRPP form, that the participant was "working for pay" at the time of injury. Since CHIRPP paper-based forms completed before 2011 asked about the context in which the injury occurred, records where the context was coded as "on duty at work" were also extracted as work injuries. Narratives describing injury events as reported by the participant were reviewed, and the job performed at the time of injury was coded into one of 11 categories corresponding to the National Occupational Classification for Statistics 2006 codes based on skill level and tasks performed (http://www.statcan.gc.ca/eng/ subjects/standard/soc/2006/noc2006menu). ${ }^{17}$ If the occupation could not be ascertained from the narrative alone (e.g. accidentally cut at work), the place where the injury occurred was used to determine the occupation (e.g. restaurant kitchen).

Occupations in the military are highly varied and can be classified in a manner similar to civilian occupations; ${ }^{17}$ however, because of the uniform organizational environment of these injuries, they were included as a separate group denoting jobs in the military as a whole.

\section{Injury characteristics}

The "most severe" nature of injury (NOI), as designated by the attending clinician, was used to define the injury characteristics. Due to the small frequencies of some types of injuries, these were further collapsed based on a matrix considering similarity between injury types/affected body parts and potential for misclassification. ${ }^{18}$ Musculoskeletal injuries included sprains/strains, injuries to muscle or tendon, not-otherwise-specified soft tissue injuries, and pulled elbows. ${ }^{19}$

\section{Statistical analysis}

We calculated descriptive frequency distributions for categorical and means/standard 
deviations (SDs) for continuous demographic and injury characteristics by occupational injury status, job group and hospital admission status. Proportionate injury ratios (PIRs) were calculated to compare the relative occurrence of NOIs between occupationally and non-occupationally injured youth overall, by job group, and by age category. ${ }^{20}$ The PIR is a ratio of the observed age- and sex-specific cases (1-year age groups for the overall and age category calculations; $<15$ years and $\geq 15$ years for the job group calculations) in the occupationally injured subgroup to the expected cases based on incidence in the nonoccupationally injured group. The PIR was calculated for each collapsed NOI category with $95 \%$ confidence intervals (CIs) to determine statistical significance. ${ }^{21}$ A PIR greater than 1 indicates that the observed NOI in the occupationally injured subgroup is more common than the expected, based on the NOI occurring in the non-occupationally injured referent group. The PIR has been used in previous injury studies ${ }^{22-24}$ and is a useful measure for assessing injury event frequency when population denominator information is unavailable. $^{25}$

All statistical analyses were completed using SAS software version 9.4 for Windows $^{26}$ and Microsoft Excel 2010.

\section{Results}

We initially extracted a total of 835888 records of injuries in 10 to 17 year olds from 1991-2012 from the paper-based and eCHIRPP forms. We excluded 167 records that did not record the injured youth's sex. Of 5983 records coded as "work" injuries and 102 records indicating the injury occurred while "on duty at work" (from “context" variable, "work" coded as 0, pre2011), 7 records were removed because they were probably record duplicates of a unique injury event. A further 32 were recoded as non-work as the narrative conclusively indicated the injury occurred neither at work nor in a work-like environment (e.g. “... Injured while taking acting lessons in a school drama class"). The dichotomous "work" question on the CHIRPP form was affirmatively marked in 14 records, although the narratives noted the youth were volunteering. However, we kept these as work injuries in the analyses because of the diversity of the informal jobs youth do that may not entitle them to payment, yet are similar to paid jobs in terms of tasks, environments and exposure to risk. ${ }^{5,6}$

The final study population consisted of 6046 work injuries and 829668 non-workrelated injuries. As very few ( $\mathrm{n}=143$, $<0.02 \%$ ) injuries resulting in fatality following ED presentation were captured in our data, and none were work injuries, we retained them in the analysis as part of the non-work-related injuries used to generate the standard proportions.

Table 1 shows sex-stratified characteristics of injuries by occupational status. Males made up the majority of both work and non-work injuries (63.9\% vs. $61.7 \%$ ), and youth injured on the job were, on average, approximately 2.5 years older than nonwork-injured youth. Notably, 17-year-old males made up a quarter of youth with work injuries and youth under 12 made up less than $3 \%(n=173)$. The five most common NOIs (open wounds, musculoskeletal injuries, superficial wounds, fractures, and burns) made up $83 \%$ of total work injury events. Youth who presented with non-occupational injuries were more frequently admitted to hospital than were those who reported work injuries $(5.4 \%$ vs. $2.8 \%$ ), and males were more frequently admitted to hospital in both groups. Males and females experienced different types of injuries; $36.5 \%$ of work-injured males experienced open wounds compared to $24.9 \%$ of females, and $28.1 \%$ of workinjured females presented with musculoskeletal injuries compared to $19.0 \%$ of males. Similar patterns in injuries by sex were observed for work and non-work injuries, though to differing magnitudes.

Table 2 shows sex and age group distributions of work-related injuries and hospital admissions by job group. Of the ED visits due to work injuries, $35.4 \%$ ( $n=2141$ ) were youth in food and beverage jobs (54.6\% males, $\mathrm{n}=1168$ ). Males made up the greater percentage of injuries among those who work in trades (construction/ repair, machinist/metal working/electrical and general labourers), as material handlers/vehicle operators and in the primary industry (logging/forestry, mining, fishing, and agricultural-related) job groups, while work injuries in females were concentrated in those in service and recreation support jobs. The relative contribution of each job group to ED visits and subsequent hospital admission varied substantially; the injured youth in the job group with the largest proportion of work-related ED visits (food and beverage workers) made up only $10.2 \%$ of work-related hospital admissions, whereas primary industry workers (76.4\% males) made up $4.8 \%$ of work-related ED visits and $24.6 \%$ of work-related hospital admissions.

We also observed differences by age groups ( $<15$ years vs. 15 years and older) in the job groups (Table 2). Older youth experienced the majority of ED visits for workrelated injuries in most groups. However, 10- to 14-year-old childcare/personal support workers and primary industry workers made up a relatively high proportion of visits to CHIRPP EDs for those job groups (40.4\% and $30.2 \%$, respectively). The delivery job group was the only category in which the majority were the youngest workers $(75.5 \%$ were aged $<15$ years $)$.

Compared to non-occupational injuries, we observed significantly elevated PIRs in occupational injuries for open wounds (PIR $=2.68$, 95\% CI: 2.59-2.78), burns (9.77, $95 \%$ CI: 8.94-10.67), eye injuries (2.50, 95\% CI: 2.20-2.83), bites (5.09, $95 \%$ CI: 4.47-5.79), crushing injuries and amputations (6.72, $95 \%$ CI: 5.79-7.80) and electrical injuries $(6.04,95 \% \mathrm{CI}$ : 3.64-10.00) (Table 3). While most agestratified PIRs did not appear to differ significantly (i.e. the CIs did not overlap), older adolescents exhibited a higher PIR for burns compared to youth aged 10 to 14 years (PIR $=10.53$, 95\% CI: 9.62-11.53 vs $\mathrm{PIR}=4.38$, $95 \% \mathrm{CI}: 2.98-6.43$ ) and youth aged 10 to 14 years had a higher PIR for bites in comparison to that of older youth (PIR $=18.48$, $95 \% \mathrm{CI}$ : $15.75-$ 21.69 vs PIR $=2.20,95 \%$ CI: $1.74-2.78)$ (Table 3).

By job group, food and beverage workers (PIR = 24.36, 95\% CI: 22.28-26.62) and trades/manufacturing workers experienced burns at a higher incidence than did nonoccupationally injured youth. Similarly, delivery workers (PIR $=36.97,95 \% \mathrm{CI}$ : 
TABLE 1

Characteristics of CHIRPP youth injury events by occupational and non-occupational status, 1991-2012

\begin{tabular}{|c|c|c|c|c|c|c|}
\hline \multirow[t]{2}{*}{ Characteristics } & \multicolumn{3}{|c|}{ Work injury } & \multicolumn{3}{|c|}{ Non-work injury } \\
\hline & All & Males & Females & All & Males & Females \\
\hline Total, n (\%) & $6046(0.72)$ & 3861 (63.9) & $2185(36.1)$ & 829668 (99.28) & 511662 (61.7) & 318006 (38.3) \\
\hline $\begin{array}{l}\text { Age in years, } \\
\text { mean (SD) }\end{array}$ & $15.8(1.5)$ & $15.7(1.5)$ & $15.8(1.5)$ & $13.1(2.1)$ & $13.1(2.1)$ & $13.0(2.1)$ \\
\hline \multicolumn{7}{|l|}{ NOI, n (\%) } \\
\hline Open wounds & 1951 (32.3) & 1408 (36.5) & 543 (24.9) & 90629 (10.9) & 64861 (12.7) & 25768 (8.1) \\
\hline $\begin{array}{l}\text { Musculoskeletal } \\
\text { injuries }\end{array}$ & 1348 (22.3) & 734 (19.0) & $614(28.1)$ & $244674(29.5)$ & $133858(26.2)$ & $110816(34.8)$ \\
\hline $\begin{array}{l}\text { Superficial, } \\
\text { including minor } \\
\text { cuts and } \\
\text { abrasions }\end{array}$ & 731 (12.1) & 441 (11.4) & $290(13.3)$ & 126507 (15.2) & 74427 (14.5) & 52080 (16.4) \\
\hline $\begin{array}{l}\text { Fractures/ } \\
\text { dislocations }\end{array}$ & $538(8.9)$ & $350(9.1)$ & 188 (8.6) & 225707 (27.2) & 153128 (29.9) & 72579 (22.8) \\
\hline Burn/corrosion & $448(7.4)$ & $223(5.8)$ & $225(10.3)$ & $5469(0.7)$ & $3064(0.6)$ & $2405(0.8)$ \\
\hline Eye injuries & 225 (3.7) & $169(4.4)$ & $56(2.6)$ & 12504 (1.5) & 8537 (1.7) & 3967 (1.2) \\
\hline Head injuries & $201(3.3)$ & $112(2.9)$ & $89(4.1)$ & $58856(7.1)$ & 39577 (7.7) & $19279(6.1)$ \\
\hline Bite & $194(3.2)$ & $133(3.4)$ & $61(2.8)$ & $6438(0.8)$ & $3631(0.7)$ & $2807(0.9)$ \\
\hline $\begin{array}{l}\text { Crushing/ } \\
\text { amputation }\end{array}$ & $164(2.7)$ & $129(3.3)$ & $35(1.6)$ & $3892(0.5)$ & $2290(0.4)$ & $1602(0.5)$ \\
\hline $\begin{array}{l}\text { Foreign body, } \\
\text { excluding eye }\end{array}$ & $42(0.7)$ & $31(0.8)$ & $11(0.5)$ & $8082(1)$ & $4648(0.9)$ & 3434 (1.1) \\
\hline Poisoning & $34(0.6)$ & $26(0.7)$ & $8(0.4)$ & 19301 (2.3) & $6177(1.2)$ & $13124(4.1)$ \\
\hline $\begin{array}{l}\text { Multiple/dental/ } \\
\text { other }\end{array}$ & $24(0.4)$ & $17(0.4)$ & $7(0.3)$ & $9063(1.1)$ & $6472(1.3)$ & $2591(0.8)$ \\
\hline Electrical injury & $15(0.2)$ & $9(0.2)$ & $6(0.3)$ & $327(0)$ & $183(0.0)$ & $144(0.0)$ \\
\hline $\begin{array}{l}\text { Frostbite/heat or } \\
\text { cold stress/ } \\
\text { systemic over- } \\
\text { exertion }\end{array}$ & $11(0.2)$ & a & a & $755(0.1)$ & $494(0.1)$ & $261(0.1)$ \\
\hline $\begin{array}{l}\text { Drowning/ } \\
\text { immersion or } \\
\text { asphyxia }\end{array}$ & $9(0.1)$ & a & a & $904(0.1)$ & $512(0.1)$ & $392(0.1)$ \\
\hline $\begin{array}{l}\text { Missing, not } \\
\text { specified or } \\
\text { not detected }\end{array}$ & 111 (1.8) & $64(1.7)$ & $47(2.2)$ & $16560(2)$ & 9803 (1.9) & $6757(2.1)$ \\
\hline $\begin{array}{l}\text { Admitted to } \\
\text { hospital, n (\%) }\end{array}$ & $170(2.8)$ & 138 (3.6) & $32(1.5)$ & 44902 (5.4) & 29382 (5.7) & $15520(4.9)$ \\
\hline
\end{tabular}

Abbreviations: CHIRPP, Canadian Hospitals Injury Reporting and Prevention Program; NOI, nature of injury.

${ }^{\text {a }}$ Value suppressed, $<5$ observations in one or both sexes.

32.23-42.41) and childcare/personal support workers (PIR $=29.27,95 \%$ CI: $21.08-$ 40.63) had a higher than expected incidence of bites (Table 4). Crushing/amputation injuries had consistently elevated PIRs across all manual/goods producing job groups, particularly in other trades/manufacturing workers (PIR $=22.68,95 \% \mathrm{CI}$ : 15.34-33.54). This group, which includes metalworkers such as welders, also had the highest proportional incidence of eye injuries $(\mathrm{PIR}=13.01,95 \%$ CI: 10.11-16.74).
While head injuries did not occur more than expected among all pooled work injuries, youth working in arts/recreation/ entertainment jobs experienced a significantly greater incidence of head injuries relative to youth with non-work injuries $(\mathrm{PIR}=1.34,95 \%$ CI: 1.01-1.77) (Table 4).

Table 5 shows the most common injuries within each job group. Crushing/amputation injuries were seen in less than $3 \%$ of work-related youth presentations to
CHIRPP EDs, but were more common among primary industry and material handlers/ vehicle operators, and represented almost one-fifth of work-related hospital admissions ( $\mathrm{n}=29,17.1 \%$; data not shown). Musculoskeletal injuries were common among young service sector workers and material handlers, although they did not occur more commonly in work injuries relative to non-work injuries as reflected in the PIRs. Other injuries, such as open wounds and burns in food/ beverage workers, and bites in delivery workers, were both common and were significantly elevated among youth with work injuries in comparison to youth with non-occupational injuries.

\section{Discussion}

Consistent with previous literature, our study found that youth who reported work-related injuries in EDs were predominantly male, a reflection of characteristic job type distributions by sex. Most injuries occurred while working in service sector jobs, particularly food and beverage service occupations, although the injuries that occurred while working in trades, manufacturing and primary industry more often resulted in hospital admission. We also demonstrated that, aside from experiencing an elevated proportional incidence of burns, crushing/amputations, bites, electrical injuries, eye injuries and open wounds overall, youth had significantly higher proportional incidences of specific injury types unique to each occupational group and age category.

A study that examined work injuries across age groups found adolescents had a rate of permanent impairment as a result of amputations, burns and cuts higher than that of adults. $^{7}$ This pattern was reflected in our data, in which open wounds (which included more severe cuts), burns and crushing injuries/amputations made up almost half of work injuries. Similarly, recent findings from an American study analyzing ED records showed that workers aged 15 to 19 years experienced burns at more than double older workers' rate. ${ }^{27}$ As in our study, burns were highest among workers in accommodation and food services, agriculture, manufacturing and construction. 


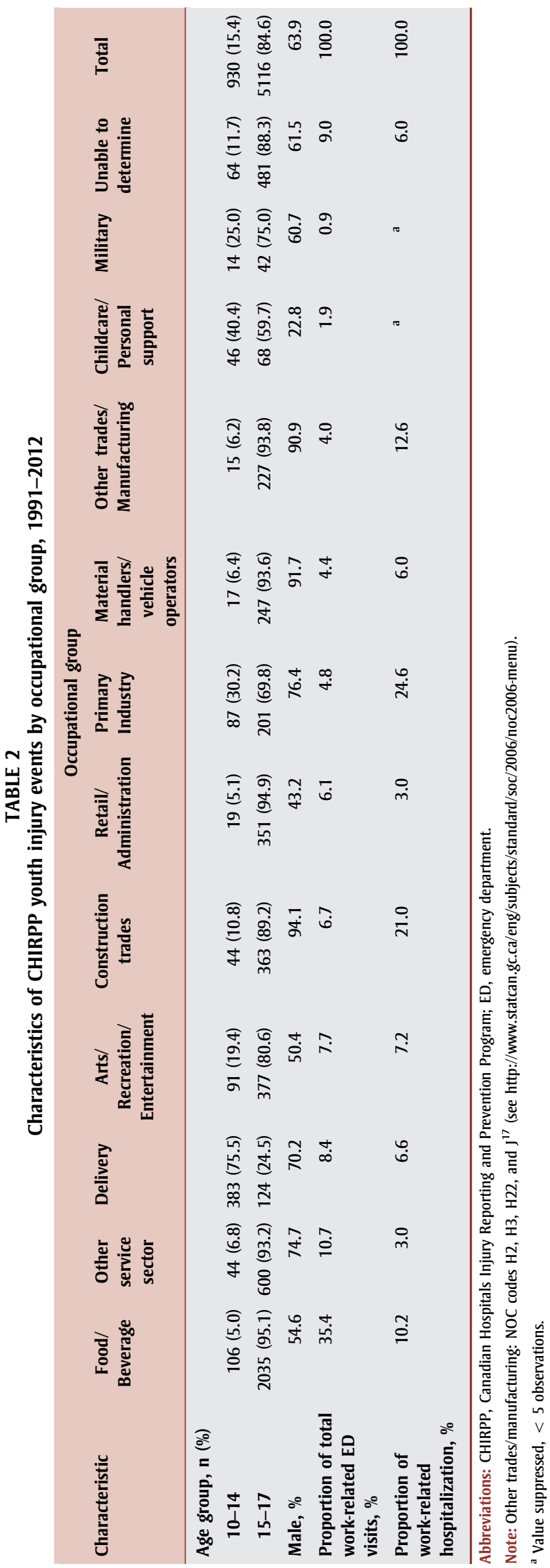

We observed a particularly high PIR for burns in older adolescent food and beverage workers; given that only $26.1 \%$ of teen workers exposed to burn hazards report using burn protection (e.g. oven mitts), ${ }^{28}$ strategies to reduce barriers to protective equipment use may be valuable in reducing a primary cause of injury in young people in these common occupations.

Eye and crushing/amputation injuries were almost universally higher in all job groups relative to non-work events, particularly in the trades, manufacturing and primary industry jobs. Previous studies that observed eye injuries in adult construction workers attributed this in part to inadequate eyewear. ${ }^{29}$ We did not investigate the use of personal protective equipment in our study; however, younger workers may perceive lower risks of eye injury and be less likely to use eye protection. ${ }^{30}$ Of note, given the increased potential for permanent impairment, ${ }^{7}$ the elevated PIRs and high frequency of hospitalization for crushing/amputation injuries emphasizes the importance of identifying effective protection measures for youth working with hazards. Our observation that the PIR for this injury type in youth aged 10 to 14 years was on par with that in older adolescents indicates that the youngest workers in some work environments may be exposed to conditions, equipment or tasks that do not reflect their skill level.

The low PIRs of musculoskeletal injuries may reflect lower rates of repetitive strain injuries in younger workers compared to older ones. ${ }^{31}$ Despite their low relative incidence, these were still common workrelated injuries in youth in our study, particularly among females. Given the potential for persistent or prolonged health care use $^{8}$ plus the increase in work-related musculoskeletal injuries that occurs with age, our findings support recommendations to prioritize injury prevention efforts early in the work life. ${ }^{7}$

Of note, we observed a higher PIR for head injuries among young arts/recreation/ entertainment workers that was not evident in the pooled PIRs. These workers were primarily camp counsellors, lifeguards and other recreational leaders/instructors. This 
TABLE 3

Age- and sex-adjusted proportional injury ratios of the nature of youth occupational injuries compared to non-occupational injuries, by age group, 1991-2012

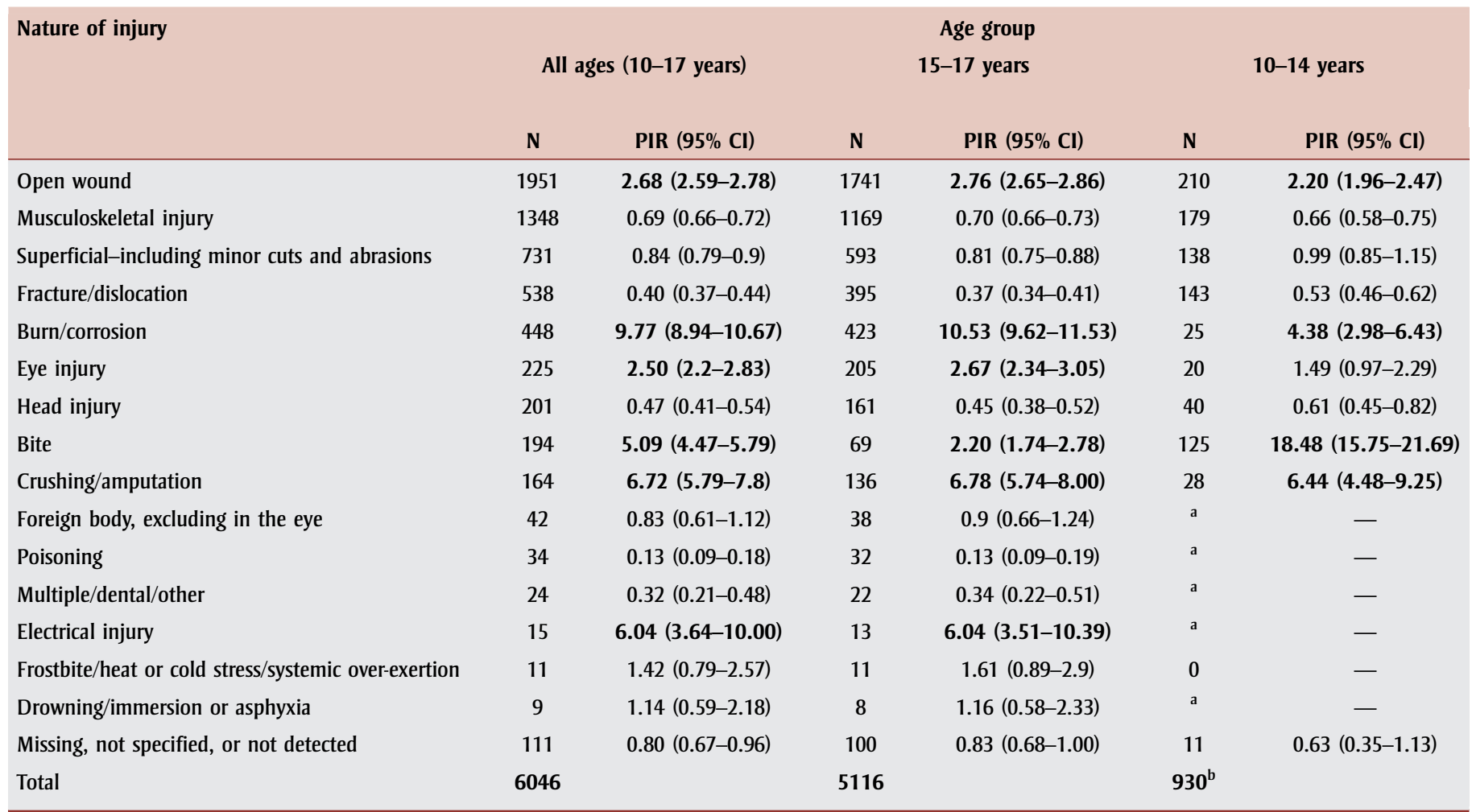

Abbreviations: $\mathrm{Cl}$, confidence interval; NOI, nature of injury; PIR, proportional injury ratios.

Note: Bolded values indicates significantly elevated PIRs, lower $95 \% \mathrm{CI}$ bound $>1$.

a PIR not shown for NOI where $\mathrm{N}<5$.

${ }^{\mathrm{b}}$ Total includes NOI categories where $\mathrm{N}<5$.

injury burden may reflect their contextual similarity to sports injuries, which typically represent a large proportion of head injuries in youth. ${ }^{32}$ As even mild traumatic brain injuries at younger ages have been associated with lower education attainment and employment status, ${ }^{33}$ the consequences of these injuries can be long-lasting.

The heterogeneity of the injuries across jobs raises the question of best ways to protect young workers. A survey of working 14- to 18-year-old Ontarians reported that although over $90 \%$ received safety training, $38 \%$ were unsupervised for at least part of the workday. ${ }^{11}$ While we were unable to assess supervision status in our study, youth working as recreational instructors or childcare providers (e.g. babysitters) or in delivery are often supervisors themselves or work alone. Our observation of significantly elevated PIRs for head injuries (arts/recreation workers) and bites (childcare and delivery workers) in these groups may reflect the inherent lack of supervision. This is salient in light of the younger age of many of these workers. In such cases, it may be more feasible to emphasize the use of any safety equipment or to strengthen training before job commencement.

\section{Strengths and limitations}

Our analysis was strengthened by expanding beyond basic descriptive analysis with the application of age- and sex-adjusted PIRs, with which we were able to statistically assess differences in NOI incidence between work injury subgroups and a nonwork-injury reference population. The PIRs calculated are in comparison to nonoccupational injuries, and are therefore dependent on the distribution of injuries in this referent population and are not interpretable as rates. However, they are nevertheless informative in that this may provide clues into underlying mechanisms of observed injury patterns. Using head injuries as an example, the mostly depressed PIRs suggest that, in addition to head injuries being more common in non-occupational injuries, it is possible that measures to prevent head injuries in young workers in some jobs, e.g. requiring hard hat use on work sites, may be conferring a protective effect. Comparing incidence of work injuries in relation to non-work injuries using the PIR allows us to consider contextual factors unique to occupational environments that may result in different injury patterns or types.

We applied a nationally standardized occupational classification system (NOC-S) to our data to present a more nuanced depiction of the jobs youth were performing when they were injured. Using this scheme allows comparison to national statistics collected from data sources such as the Labour Force Survey. ${ }^{34}$ The strong consistency between our results and those published in the literature also indicates that youth job data from CHIRPP records coded using the NOC-S guidelines are comparable 


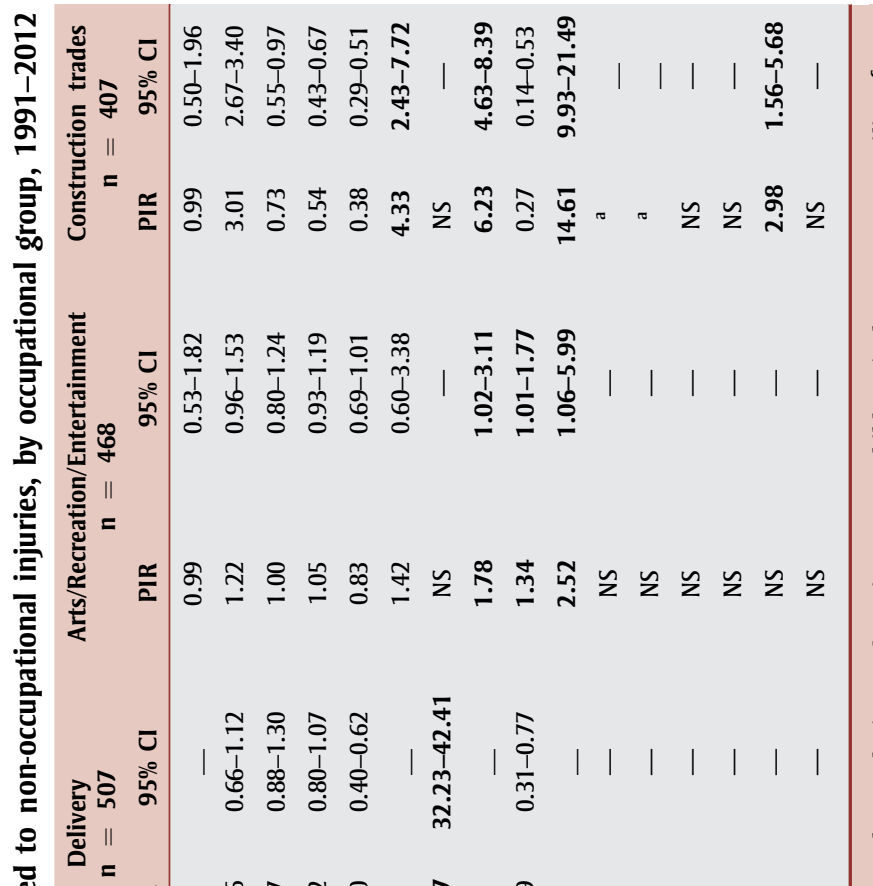

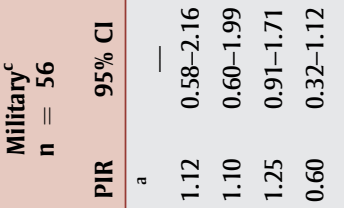

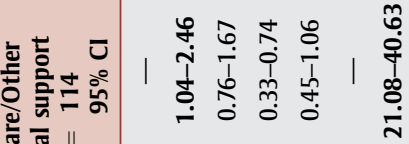

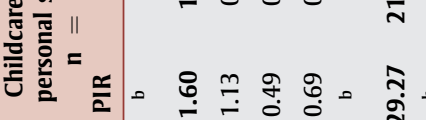

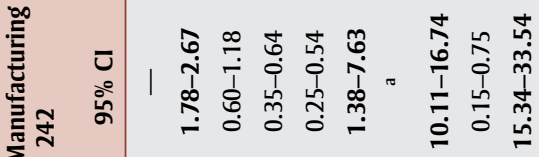

密 $=$

产

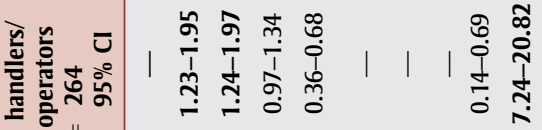

带

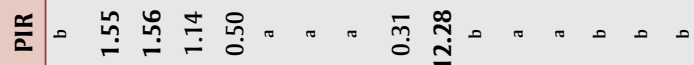

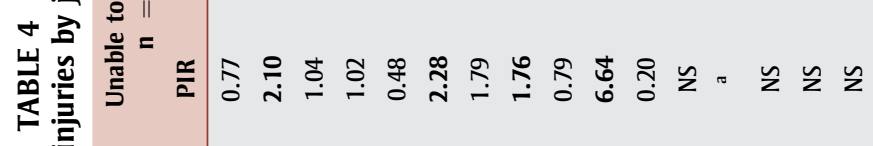

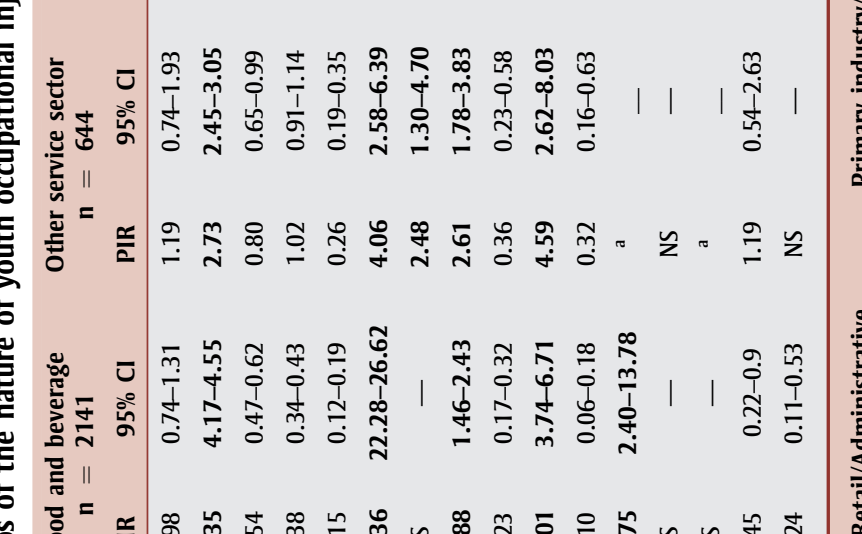

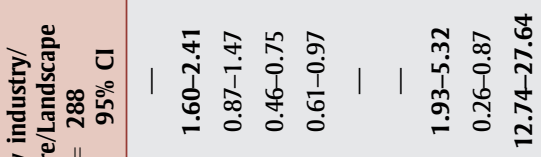

售意

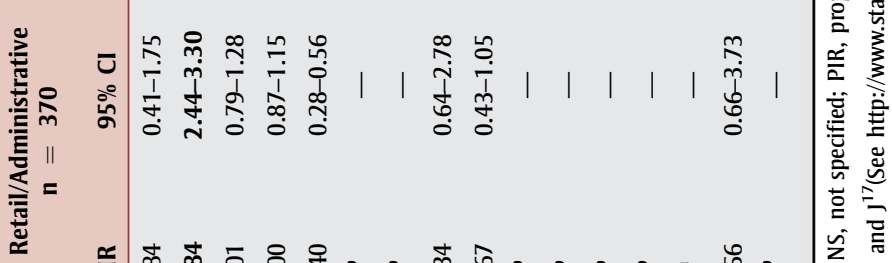

言

흘 응

홍 를 를

들

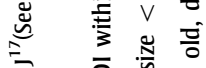

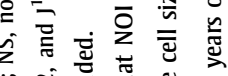

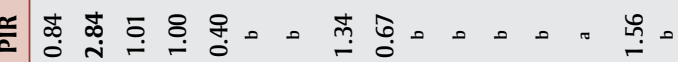

高

몰

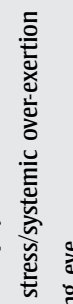

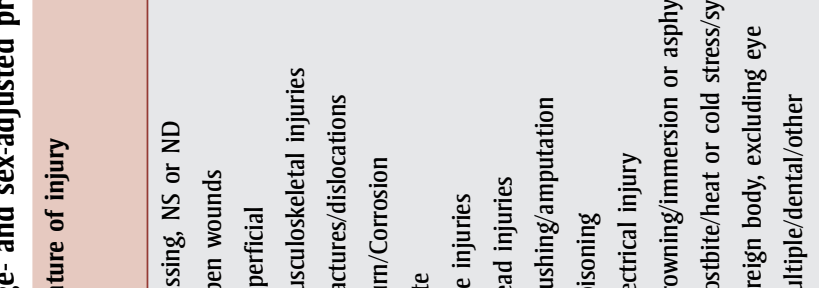

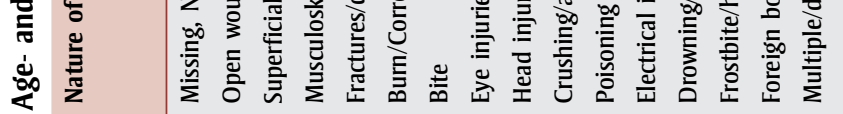
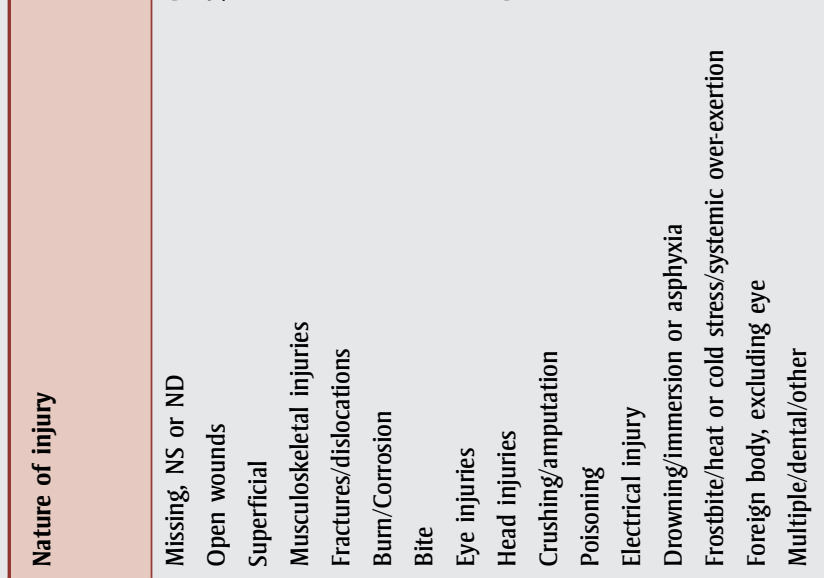

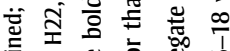

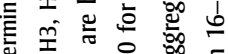

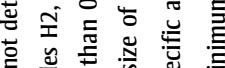

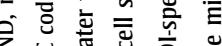

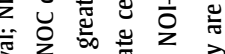

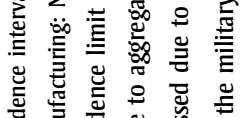

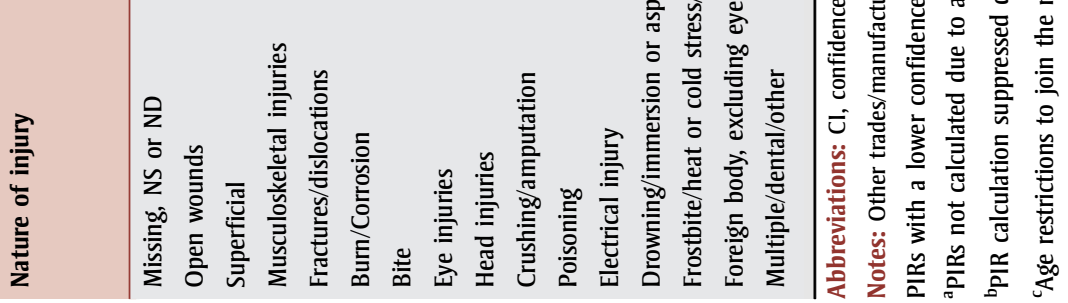




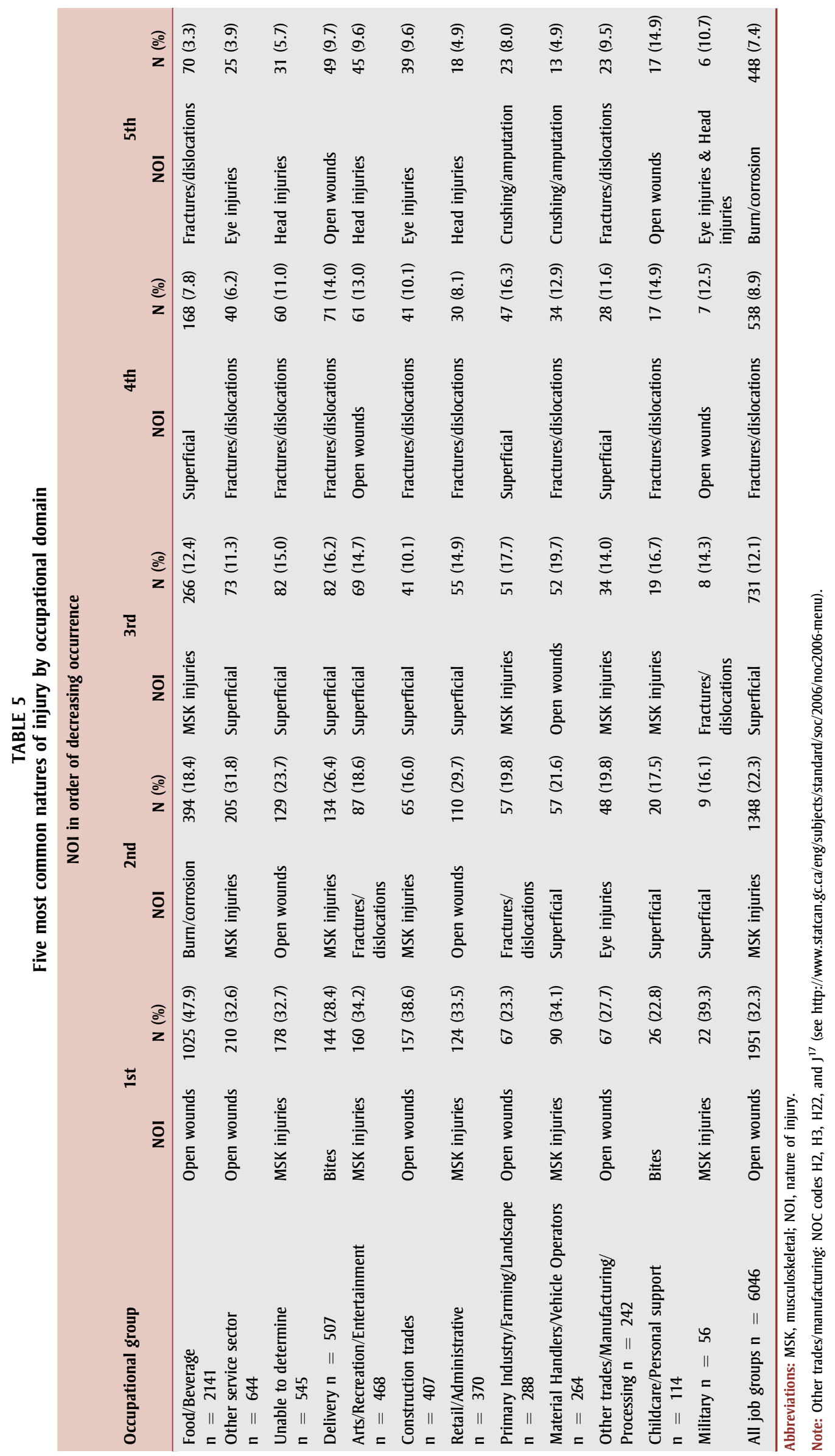


to other studies investigating youth work injuries using different criteria. Although this classification scheme precludes attributing injury incidence to specific jobs, NOC groups classify jobs involving comparable tasks or duties, education requirements and environments together. Therefore, jobs within a group are likely to expose workers to similar types of hazards. A limitation of this method is that there is no standardized algorithm for assigning jobs or tasks.

Our study also has several limitations, which may affect the results. Most CHIRPP EDs are not population-based as they are strategically located sentinel sites for the purpose of active surveillance. Certain groups are underrepresented, including older teens and residents of rural or remote areas; therefore, injury types and job groups unique to these areas and populations may be underestimated in our analysis. Injuries requiring admission are more likely to be missed at CHIRPP sites; our estimates likely understate the frequency of more severe youth injuries. ${ }^{16}$ However, injury characteristic data collected from several CHIRPP sites hypothesized to be fully populationrepresentative were shown to be highly correlated with data collected from a national population-based survey. Data from the population-representative CHIRPP sites were also consistent with other CHIRPP sites. ${ }^{35}$ This suggests that external validity of CHIRPP injury data may be cautiously inferred to evaluate aggregate national trends in youth injuries. ${ }^{35}$ Moreover, a study examining sports injuries among youth reported high validity of injury characteristics captured by a CHIRPP children's hospital when compared to those captured by a local administrative data source. $^{36}$ The percent of males aged 10 to 17 years presenting to CHIRPP was similar, though slightly higher than the percent of males with trauma captured by the National Ambulatory Care Reporting System (NACRS) $(61.7 \%$ vs $59.2 \%))^{37}$ the slightly older age group reported by NACRS (ages 10-19) may account for this slight difference.

At the time of data extraction, transition from CHIRPP paper records to eCHIRPP was ongoing and data from 2011 and 2012 were not complete for all sites. To assess how sensitive the job group characteristics were to inclusion of eCHIRPP records from incomplete years, the proportion of workrelated injuries for each job group was calculated using only the complete, paperbased records for injuries occurring from 1991 to 2010, and then again for the full dataset. It did not appear that the proportions of work injuries by job group were substantially affected by completeness of annual record entry as the percent change between the two calculations was less than $10 \%(-5.10 \%$ to $5.66 \%)$ for each group (results not shown). Similarly, analyses using only records for years with complete data entry (1991-2010) produced negligibly different PIRs, with no changes in significance levels (overlapping CIs), compared to analyses using all records up to 2012. For example, the PIRs and 95\% CIs for open wounds in 1991 to 2010 and 1991 to 2012 were $2.64(2.52-2.76)$ and 2.68 (2.572.80 ), respectively (results not shown).

Although the job codes were based upon a consistent method, the subjectivity of the coder may have resulted in misclassification. Although we did not perform formal validation studies, we did observe expected patterns between and within job groups for sex, age and trends in job availability. For example, ED visits for delivery job work injuries as a percent of all work-related ED visits declined from $13.5 \%$ to $4.4 \%$ between $1991-1997$ and 2005-2012, possibly coinciding with declining hardcopy newspaper circulation. The PIRs for the "Unable to be determined" records were generally reflective of the pooled PIRs, indicating ambiguous records were not clustered in a particular job group or sector, and the PIRs also demonstrated predictable injury characteristics by job group, indicating preliminary validity of our classifications. Given these signals, systematic misclassification of job coding was not evident.

\section{Conclusion}

We used a nationally standardized job classification scheme and PIRs to analyze youth occupational injuries captured by the CHIRPP surveillance system. This study adds to the growing body of evidence pointing to a greater incidence of specific injuries associated with job groups and age compared to non-occupational injuries.
These findings can be used to support targeted, age-specific prevention measures that can lead to a reduction of injuries.

\section{References}

1. Wray-Lake L, Syvertsen AK, Briddell L, Osgood DW, Flanagan CA. Exploring the changing meaning of work for American high school seniors from 1976 to 2005 . Youth Soc. 2011;43(3):1110-35.

2. Statistics Canada. Table 282-0087. Labour force survey estimates (LFS), by sex and age group, seasonally adjusted and unadjusted, monthly (persons unless otherwise noted), CANSIM (database), 2015 [Internet]. Ottawa (ON): Statistics Canada; 2015 [cited 2015 Mar 27]. Available from: http://www5.statcan.gc.ca/cansim/a26?id $=2820087$

3. Association of Workers' Compensation Boards of Canada. National Work Injury/Disease Statistics Program (NWISP). Table 24. Number of Fatalities, by Age and Jurisdiction, 20112013. Toronto (ON): AWCBC; 2013.

4. Association of Workers' Compensation Boards of Canada. National Work Injury/ Disease Statistics Program (NWISP). Table 3. Number of accepted time-loss injuries, by age and jurisdiction, 2011-2013. Toronto (ON): AWCBC; 2013.

5. Zierold KM, Garman S, Anderson H. Summer work and injury among middle school students, aged 10-14 Years. Occup Environ Med. 2004;61(6):518-22.

6. Barnetson B. Incidence of work and workplace injury among Alberta teens. Can J Work Soc. 2013;20(Summer):14-32.

7. Breslin C, Koehoorn M, Smith P, Manno M. Age related differences in work injuries and permanent impairment: a comparison of workers' compensation claims among adolescents, young adults, and adults. Occup Environ Med. 2003;60(9):E10.

8. Koehoorn M, Breslin FC, Xu F. Investigating the longer-term health consequences of work-related injuries among youth. J Adolesc Health. 2008;43(5):466-73.

9. Breslin FC, Pole JD, Tompa E, Amick BC, Smith P, Johnson SH. Antecedents of work disability absence among young people: a prospective study. Ann Epidemiol. 2007; 17(10):814-20. 
10. Galarneau D. Earnings of temporary versus permanent employees. Persp Labour Income. 2005;17(1):40-53 .

11. Lewko J, Hall K, Egeh G, Volpe R, Fuhringer C, Tremblay C. Current health and safety policies protecting young workers in Canada, 2011. Sudbury (ON): Laurentian University; 2011. Joint publication of the Ontario Neurotrauma Foundation.

12. Loughlin C, Barling J. Young workers' work values, attitudes, and behaviours. J Occup Organ Psychol. 2001;74:543-58. DOI: 10.1348/096317901167514.

13. Tucker S, Diekrager D, Turner N, Kelloway EK. Work-related injury underreporting among young workers: prevalence, gender differences, and explanations for underreporting. J Safety Res. 2014;50:67-73.

14. Curtis Breslin F, Polzer J, MacEachen E, Morrongiello B, Shannon H. Workplace injury or "part of the job" ?: Towards a gendered understanding of injuries and complaints among young workers. Soc Sci Med. 2007;64(4):782-93.

15. Lipskie T, Breslin FC. A descriptive analysis of Canadian youth treated in emergency departments for work-related injuries. Chronic Dis Can. 2005;26(4):107-13.

16. Macarthur C, Pless IB. Evaluation of the quality of an injury surveillance system. Am J Epidemiol. 1999;149(6):586-92.

17. Statistics Canada. Minister of Industry. National occupational classification for statistics (NOC-S). 2006. Ottawa (ON): Statistics Canada; 2007. [Statistics Canada, Catalogue No.12:583-XIE].

18. Barell V, Aharonson-Daniel L, Fingerhut LA, Mackenzie EJ, Ziv A, Boyko V, et al. An introduction to the Barell body region by nature of injury diagnosis matrix. Inj Prev. 2002;8(2):91-6.

19. Bhattacharya A. Costs of occupational musculoskeletal disorders (MSDs) in the United States. Int J Ind Ergon. 2014;44(3):448-54. DOI: 10.1016/j.ergon.2014.01.008.

20. Boyle P, Parkin DM. Chapter 11. Statistical methods for cancer registries. In: Jensen OM, Parkin DM, MacLennan R, Muir CS, Skeet $\mathrm{RG}$, editors. Cancer registration: principles and methods: Lyon (FR): International Agency for Research on Cancer; 1991 p. 126.
21. Breslow NE, Day NE. Statistical methods in cancer research. Volume II-The design and analysis of cohort studies. IARC Scientific Publication No. 82. Lyon (FR): International Agency for Research on Cancer; 1987.

22. Do MT, Fréchette M, McFaull S, Denning B, Ruta $\mathrm{M}$, Thompson $\mathrm{W}$. Injuries in the North-analysis of 20 years of surveillance data collected by the Canadian Hospitals Injury Reporting and Prevention Program. Int J Circumpolar Health. 2013;72:1-6.

23. Deits J, Yard EE, Collins CL, Fields SK, Comstock RD. Patients with ice hockey injuries presenting to US emergency departments, 1990-2006. J Athl Train. 2010;45(5):467-74. DOI: $10.4085 / 1062-6050-45.5 .467$.

24. Lipscomb HJ, Li L. Injuries among teens employed in the homebuilding industry in North Carolina Inj Prev. 2001;7(3):205-9.

25. Knowles SB, Kucera KL, Marshall SW. Commentary: the injury proportion ratio: what's it all about? J Athl Train. 2010;45(5):475-7.

26. SAS Institute Inc., Cary, NC, USA. SAS software, SAS system for Windows Copyright (c) 2002-2012. 20129.4.

27. Reichard AA, Konda S, Jackson LL. Occupational burns treated in emergency departments. Am J Ind Med. 2015;58 (3):290-8. DOI: 10.1002/ajim.22407.

28. Runyan CW, Vladutiu CJ, Rauscher KJ, Schulman M. Teen workers' exposures to occupational hazards and use of personal protective equipment. Am J Ind Med. 2008;51 (10):735-40. DOI: 10.1002/ajim.20624.

29. Welch L, Hunting K, Mawudeku A. Injury surveillance in construction: eye injuries. Appl Occup Environ Hyg. 2001;16(7):755-62.

30. Lombardi DA, Verma SK, Brennan MJ, Perry MJ. Factors influencing worker use of personal protective eyewear. Accid Anal Prev. 2009;41(4):755-62.

31. Breslin FC, Ibrahim S, Smith P, Mustard CAmick B, Shankardass K. The demographic and contextual correlates of work-related repetitive strain injuries among Canadian men and women. Am J Ind Med. 2013;56(10):1180-9.

32. Harvey HH. Reducing traumatic brain injuries in youth sports: youth sports traumatic brain injury state laws, January 2009-December 2012. Am J Public Health. 2013;103(7): 1249-54. DOI:10.2105/AJPH.2012.301107.
33. Anderson V, Brown S, Newitt H, Hoile H. Educational, vocational, psychosocial, and quality-of-life outcomes for adult survivors of childhood traumatic brain injury. J Head Trauma Rehabil. 2009;24(5):303-12. DOI: 10.1097/HTR.0b013e3181ada830.

34. Statistics Canada. Labour Force Survey (LFS) [Internet]. Ottawa (ON): Statistics Canada; 2015 [cited 2015 Apr 16]. Available from: http://www23.statcan.gc.ca/imdb/p2SV.pl? Function $=$ getSurvey\&SDDS $=3701$

35. Pickett W, Brison RJ, Mackenzie SG, et al. Youth injury data in the Canadian Hospitals Injury Reporting and Prevention Program: do they represent the Canadian experience? Inj Prev. 2000;6(1):9-15.

36. Kang J, Hagel B, Emery CA, Senger T, Meeuwisse W. Assessing the representativeness of Canadian Hospitals Injury Reporting and Prevention Programme (CHIRPP) sport and recreational injury data in Calgary, Canada. Int J Inj Contr Saf Promot. 2013;20(1):19.

37. Canadian Institute for Health Information. Injury and trauma emergency department statistics, 2013-2014 [Internet]. Ottawa (ON): CIHI; 2015 [cited 2015 Oct 22]. Available from: https://www.cihi.ca/en/types-of-care/ specialized-services/injury-and-traumaemergency-department-statistics-2013-2014 